\title{
Cyclin G1 overcomes radiation-induced G2 arrest and increases cell death through transcriptional activation of cyclin B1
}

\author{
HR Seo ${ }^{1}$, DH Lee ${ }^{1}$, HJ Lee ${ }^{1}$, M Baek ${ }^{2}$, S Bae ${ }^{1}$, JW Soh ${ }^{3}$, SJ Lee ${ }^{4}$, \\ $\mathrm{J} \mathrm{Kim}^{5}$ and YS Lee ${ }^{\star, 1}$ \\ ${ }^{1}$ Laboratory of Radiation Effect, Korea Institute of Radiological and Medical \\ Sciences, 215-4 Gongneung-Dong, Nowon-Ku, Seoul 139-706, Korea \\ 2 Atomic Energy Policy Division, Atomic Energy Bureau, Ministry of Science and \\ Technology, Gwacheon, Kyunggi-Do 427-715, Korea \\ ${ }^{3}$ Laboratory of Signal Transduction, Department of Chemistry, Inha University, \\ Incheon 402-751, Korea \\ ${ }^{4}$ Laboratory of Radiation Experimental Therapeutics, Korea Institute of \\ Radiological and Medical Sciences, 215-4 Gongneung-Dong, Nowon-Ku, \\ Seoul 139-706, Korea \\ ${ }^{5}$ School of Life Sciences \& Biotechnology, Korea University, Seoul 136-701, \\ Korea \\ * Corresponding author: YS Lee, Laboratory of Radiation Effect, Korea Institute \\ of Radiological and Medical Sciences, 215-4 Gongneung-Dong, Nowon-Ku, \\ Seoul 139-706, Korea. Tel: + 82-2-970-1325; Fax: + 82-2-970-2402; \\ E-mail: yslee@kcch.re.kr
}

Received 29.3.05; revised 14.10.05; accepted 17.10.05; published online 02.12 .05 Edited by M Blagosklonny

\begin{abstract}
Although cyclin $\mathrm{G} 1$ has been implicated in certain p53-related biological phenomena, other aspects of its function remain unclear. Here we report hitherto unknown mechanism by which cyclin G1 increases radiation sensitivity by regulating the level of cyclin B1. Overexpression of cyclin G1 was observable in lung carcinoma tissues. Irradiation of human lung cells with cyclin $\mathrm{G} 1$ overexpression resulted in increased cell death and $\gamma-\mathrm{H} 2 \mathrm{AX}$ foci suggesting that cyclin G1 rendered the cells more susceptible to DNA damage. Enhanced radiosensitivity by cyclin G1 was correlated with increased cyclin B1, CDC2/cyclin B1 complex, and MPM2. Cell cycle synchronization clearly showed coexpression of cyclin $\mathrm{G} 1$ and cyclin B1 in G2/M phase. Depletion of cyclin G1 by interference RNA revealed that cyclin G1 regulated transcription of cyclin B1 in a p53-independent manner, and confirmed that the increased mitotic cells and cell death by cyclin G1 were dependent upon cyclin B1. Therefore, our data suggest that cyclin G1 enhanced radiation sensitivity by overriding radiation-induced G2 arrest through transcriptional upregulation of cyclin B1.

Cell Death and Differentiation (2006) 13, 1475-1484. doi:10.1038/sj.cdd.4401822; published online 2 December 2005
\end{abstract}

Keywords: cyclin G1; radiation-induced G2 arrest; radiosensitive; transcriptional activation of cyclin B1

Abbreviations: CDK5, cyclin-dependent kinase 5; GAK, cyclin $G$ associated kinase; siRNA, interference RNAs

\section{Introduction}

Cyclin G1, which is one of the target genes of $p 53$, has been investigated for its roles relevant to $p 53$ activities. ${ }^{1,2}$ However, recent observations suggest that cyclin $\mathrm{G} 1$ might be involved in various p53-independent activities. Cyclin $\mathrm{G} 1$ is associated with cyclin-dependent kinase 5 (CDK5) and non-CDK-serine/ threonin kinase, named cyclin $\mathrm{G}$ associated kinase (GAK). ${ }^{3,4}$ In addition, cyclin $\mathrm{G} 1$ has been suggested to act as an oncogenic protein, because of its overexpression in human tumor cells. ${ }^{5,6}$ On the other hand, cyclin $G$ is also involved in G2/M arrest in response to DNA damage ${ }^{7}$ or in the facilitation of TNF-induced apoptosis, ${ }^{8}$ implicating tumor suppressive function. Despite these findings, understanding of the biochemical function of cyclin G1 in complex with associated partners and of the molecular function of association partners in cellular physiology has been limiting.

In response to IR cells induce checkpoints at G1/S, S, and $\mathrm{G} 2 / \mathrm{M}$ phases as well as cell death or apoptosis. ${ }^{9}$

Within the cell cycle, both G1-S and G2-M phase transitions are under constant surveillance for the protection of cells from exogenous and endogenous DNA-damaging agents. These ordered dependencies are controlled by the regulation of certain gene products, whose mutations can result in altered stress responses, increased mutation rates, or genetic instability. ${ }^{10}$ Exposure to DNA-damaging agents, such as ionizing radiation, results in cell cycle arrest, thereby allowing the damaged chromosomes to be repaired before the cell progresses to mitosis. Therefore, investigation of the genetic mechanisms of cell cycle checkpoints is highly expected to contribute to an understanding of both cancer development and responses of cells to chemotherapy and radiotherapy. Progression from the G2 phase into mitosis requires the following: the binding of cyclin B1 to CDC2, a series of phosphorylation and dephosphorylation events on both of these subunits, and translocation of the CDC2-cyclin B1 complex to the nucleus. ${ }^{11}$ Before mitosis, active CDC2 is held in an inactive state by phosphorylation $^{12,13}$ and, at the end of G2, rapid dephosphorylation of CDC2 at Thr-14 and Tyr-15 results in entry into mitosis. ${ }^{14,15}$ The rapid dephosphorylation of CDC2 probably involves simultaneous inactivation of the Wee1/Myt 1 kinases together with the activation of the dual specificity CDC25C phosphatase, which in turn dephosphorylates CDC2 at Thr-14, followed by Tyr-15. ${ }^{16}$

In our previous study, radiation response genes were identified from the peripheral blood lymphocytes by using microarray system. One of the genes, cyclin G1 was correlated by $92 \%$ with radiation responsiveness in ex vivo irradiated human lymphocytes. ${ }^{17}$ In order to investigate molecular mechanism how cyclin $\mathrm{G} 1$ affects radiation response, we examined (1) cyclin G1 expression in cancer tissues; (2) effects of cyclin G1 overexpression on cell cycle and (3) G2 
arrest defect by cyclin G1. Cyclin G1 was relatively overexpressed in several cancer tissues, including lung as assessed by tissue array system. Cyclin G1 overexpression in lung carcinoma or fibroblast cells overcame radiationinduced G2 arrest by transcriptionally activating cyclin B1 and this in turn resulted in increased radiation sensitivity.

\section{Results}

\section{Cyclin G1 overexpression facilitated radiation induced growth inhibition and cell death}

Cyclin G1 has frequently been reported to be overexpressed in cancer tissues. ${ }^{5,6,18}$ Our immunocytochemical analysis by using tissue array revealed that tissues of lung carcinoma (Figure 1a), astrocytoma, melanoma, thyroid gland carcinoma, breast carcinoma, liver carcinoma, and cervix cancer (data not shown) overexpressed cyclin G1 protein. To examine the response to radiation in cyclin $\mathrm{G} 1$ overexpressing cells, cyclin G1 was transfected to lung cells such as $\mathrm{NCl}$ $\mathrm{H} 460$ and WI38 cells by using retroviral vector system (Figure 1b). Clonogenic survival of both $\mathrm{NCl}-\mathrm{H} 460$ and WI38 cells was inhibited by cyclin G1 overexpression. Radiationinduced growth delay was also facilitated by cyclin G1 overexpression, when Trypan blue dye exclusion assay was used (Figure 1c). At $48 \mathrm{~h}$ after $5 \mathrm{~Gy}$ radiation, cell death shown by $\mathrm{PI}$ staining was significantly increased (Figure 1d). Since the presence and the rate of loss of histone H2AX foci are correlated with cellular radiosensitivity, ${ }^{19}$ phosphorylated H2AX on serine 139 was examined by Western blotting analysis: Because phosphorylated $\mathrm{H} 2 \mathrm{AX}$ can be visualized as foci by immunofluorescence using phosphospecific antibodies, foci formation was also examined. Phosphorylated $\mathrm{H} 2 \mathrm{AX}$ was increased at 24 and $48 \mathrm{~h}$ after radiation with further potentiation by cyclin $\mathrm{G} 1$. Figure $1 \mathrm{e}$ and $\mathrm{f}$ shows that radiation induced $\mathrm{H} 2 \mathrm{AX}$ foci were significantly increased by cyclin $\mathrm{G} 1$ overexpression.

\section{Cyclin G1 overexpression inhibited radiation-induced $\mathrm{G} 2$ arrest}

To elucidate the mechanisms of cyclin G1-mediated increased radio-sensitivity, cell cycle distribution was examined after radiation. As shown in Figure $2 a$, radiation-induced G2/M arrest was increased by cyclin $\mathrm{G} 1$ overexpression in both $\mathrm{NCl}$ $\mathrm{H} 460$ and WI38 cells: $12 \mathrm{~h}$ of radiation induced $40 \%$ G2/M arrest in control cells and 64\% G2/M arrest in cyclin G1 overexpressing $\mathrm{NCl}-\mathrm{H} 460$ cells. At $24 \mathrm{~h}$ after radiation, $30 \%$ $\mathrm{G} 2 / \mathrm{M}$ in the control and $52 \%$ in the cyclin $\mathrm{G} 1$ overexpressing cells. Similar pattern was also observed in the case of WI38 cells. To elucidate whether cyclin $\mathrm{G} 1$ affected $\mathrm{G} 2$ or $\mathrm{M}$ phase, ${ }^{20}$ morphological analysis after Giemsa staining was performed. Radiation-induced mitotic index was significantly increased by cyclin $\mathrm{G} 1$ in both $\mathrm{NCl}-\mathrm{H} 460$ and WI38 cells (Figure $2 b$ ). In addition, MPM-2 protein, which is known to be expressed in mitotic cells, was more predominantly expressed in cyclin $\mathrm{G} 1$ overexpressing $\mathrm{NCl}-\mathrm{H} 460$ cells and WI38 cells (Figure 2c). When examined by Hoechst 33258 staining at 24 and $48 \mathrm{~h}$ after radiation (data of $24 \mathrm{~h}$ are not shown), multinuclear and giant cells were significantly increased in both the cyclin G1 overexpressing cells (Figure 2d). When cell cycle regulators, which are involved in G2-M transition, were examined, basal levels of cyclin B1 and its counterpart kinase, CDC2 activity were increased in cyclin G1 overexpressing $\mathrm{NCl}-\mathrm{H} 460$ and WI38 cells, whereas the expression of inactive phospho-CDC2 was decreased. The expressions of broad range of CDK inhibitors, p21 were decreased and cyclin B1 bound p21 proteins were also inhibited in cyclin G1 overexpressing cells, suggesting that cyclin G1 facilitated protein activities, which are involved in G2-M transition (Figure 3a). When the cells were irradiated, these phenomena were more predominant. Radiation-induced p21 expressions were attenuated by cyclin $\mathrm{G} 1$ overexpression in $\mathrm{NCl}-\mathrm{H} 460$ and WI38 cells, whereas radiation-induced cyclin B1 expression was potentiated. Increase of CDC2 kinase activity and CDC2-cyclin B1 complex in response to radiation, which was accompanied with lower expression of phospho-CDC2 protein, was shown in cyclin G1 overexpressing cells, suggesting that cyclin $\mathrm{G} 1$ overexpression overcame radiation-induced $\mathrm{G} 2$ arrest in cell cycle regulation (Figure $3 \mathrm{~b}$ ). The expression levels of p53 were not different between the control and the cyclin G1 overexpressing cells with or without radiation.

\section{Cyclin G1 was predominantly expressed in G2/M phase in cell cycle progression}

Since cyclin G1 regulates G2-M transition, it appears to be quite logical to speculate that cyclin $\mathrm{G} 1$ expression correlates with cell cycle distribution. After $200 \mu \mathrm{M}$ mimosine treatment, which synchronizes cells at G1 phase, the amount of mitotic cells peaked at $12 \mathrm{~h}$. This mitotic index coincided with the peak of G2/M phase with further augmentation by cyclin $\mathrm{G} 1$ overexpression (Figure 4a). Timing of cyclin G1 and cyclin B1 expression also overlapped with maximum at $12 \mathrm{~h}$, when G2/M phase peaked. The expression pattern disappeared afterward as cell cycle transited from G2/M to $\mathrm{G} 1$ phase (Figure 4b). Immunofluorescence data of cyclin G1 overexpressed cells also indicated that cyclin $\mathrm{G} 1$ and cyclin $\mathrm{B} 1$ was maximum at $12 \mathrm{~h}$ after mimosine wash-out, when G2/M phase peaked.

\section{Cyclin G1 regulated cyclin B1 expression in a p53-independent manner}

Since cyclin G1 overexpression increased cyclin B1 expression and their expression was correlated with each other, we next examined whether cyclin G1 controlled cyclin B1 expression, by using interference RNAs (siRNA) for cyclin $\mathrm{B} 1$ and cyclin $\mathrm{G} 1$ in $\mathrm{NCl}-\mathrm{H} 460$ and WI38 cells. As seen in Figure 3, siRNA of cyclin G1 (siG1) efficiently depleted cyclin $\mathrm{G} 1$ protein level in dose-dependent manner, whereas control siRNA (siCont) treatment did not. Interestingly, siG1 diminished cyclin B1 protein level whereas cyclin B1 inhibition with cyclin B1 siRNA (siB1) did not affect cyclin G1 expression (Figure 5a), suggesting that cyclin $\mathrm{G} 1$ is an upstream molecule for cyclin B1 expression. Since cyclin $\mathrm{G} 1$ has been reported to be regulated by $p 53,{ }^{7,21}$ we examined whether cyclin $\mathrm{B} 1$ regulation by cyclin $\mathrm{G} 1$ was dependent on $\mathrm{p} 53$. 
a

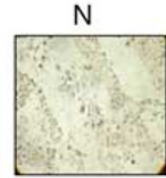

Squamous cell carcinoma
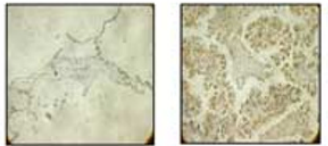

Papillary adenocarcinoma

b

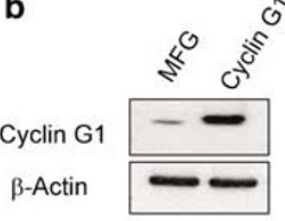

$\mathrm{NCl}-\mathrm{H} 460$
T
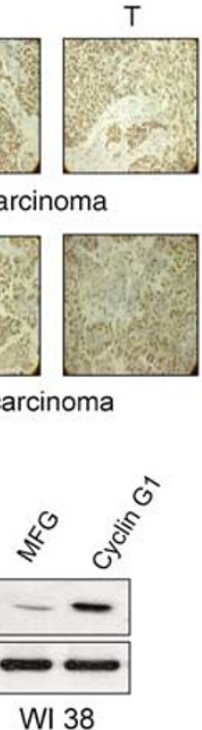
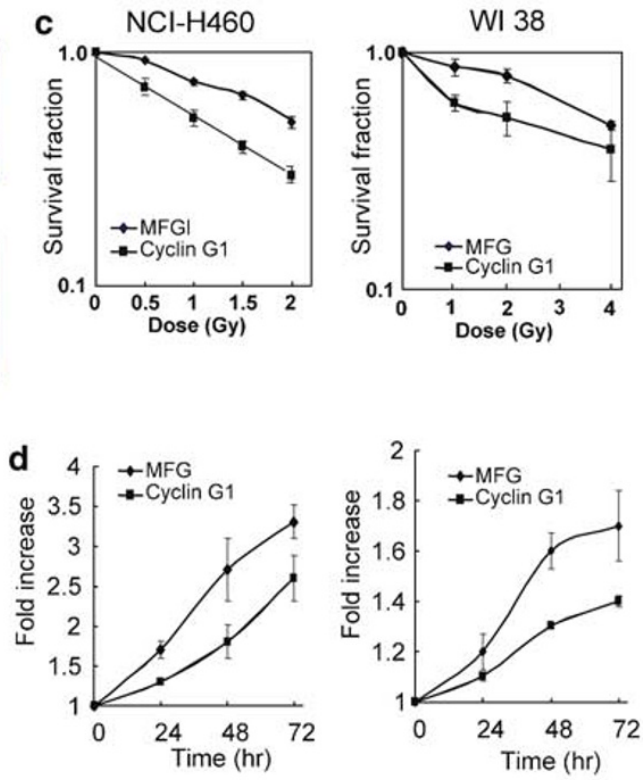

$\mathrm{NCl}-\mathrm{H} 460$

WI 38

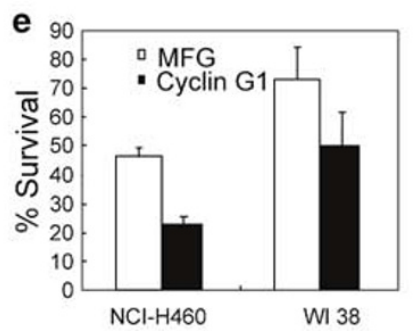

g $\square$ MFG

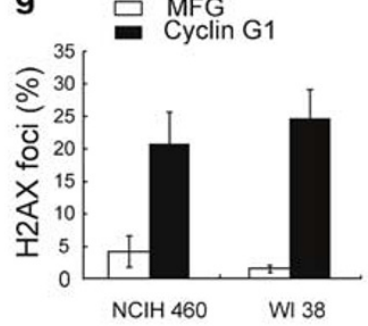

f

MFG

Cyclin G1

$\mathrm{IR}(\mathrm{hr})$

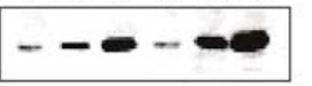

$p-H 2 A X$

$\mathrm{NCl}-\mathrm{H} 460$

-

WI 38

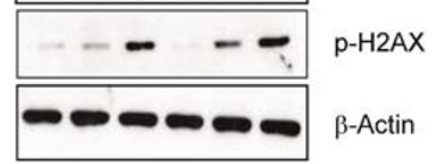

Figure 1 Effects on radiation induced growth inhibition and cell death by cyclin G1. (a) Immunohistchemistry for cyclin G1 was performed using the sections of tissue microarray. Antibody was detected by the aminobenzidine method that produces brown color. N: normal lung tissue; T: lung tumor tissue B. Western blot analysis for cyclin G1 in control and cyclin G1 transfected cells (b). Colony forming assay after various doses of radiation (c), Trypan blue dye exclusion assay after $5 \mathrm{~Gy}$ radiation (d) and $\mathrm{PI}$ staining at $48 \mathrm{~h}$ after $5 \mathrm{~Gy}$ radiation (e) were performed in control or cyclin $\mathrm{G} 1$ overexpressed cells. Western blot analysis for phospho-H2AX was done at indicated time points of 5 Gy radiation $(\mathbf{f})$ and $\gamma-\mathrm{H} 2 \mathrm{AX}$ foci at $48 \mathrm{~h}$ after $5 \mathrm{~Gy}$ radiation $(\mathbf{g})$ were examined using fluorescent microscopy. Results are means and standard deviation of three independent experiments

Treatment of siRNA for p53 (sip53) inhibited cyclin B1 expression as well as cyclin $\mathrm{G} 1$ expression. However, when cyclin $\mathrm{G} 1$ expression vector was additionally transfected to sip53 treated cells, the level of both cyclin G1 and cyclin B1 expression was restored to that of cyclin $\mathrm{G} 1$ overexpressing cells, even though p53 expression was still intact (Figure 5b). These results suggest that cyclin $B 1$ regulation by cyclin $\mathrm{G} 1$ is independent of $\mathrm{p} 53$. To determine whether treatment of siB1 as well as siG1 restored cylcin G1-mediated phenomena, the expression of $\mathrm{p} 21$ protein and histone $\mathrm{H} 2 \mathrm{AX}$ was examined.
Decreased expression of p21 and increased expression of MPM-2 by cyclin G1 was restored to the level of the control cells by treatment of both siB1 and siG1, suggesting that cyclin G1-mediated phenomena were cyclin B1 dependent (Figure $5 \mathrm{c}$ ). In fact, when the expression vector of cyclin $\mathrm{G} 1$ or cyclin B1 was transiently transfected, the results corroborated our hypothesis (Figure $5 \mathrm{~d}$ ). The expressions of p21 and phospho-CDC2 were inhibited by cyclin B1 overexpression, which corresponded well with the results by cyclin $\mathrm{G} 1$ overexpression. 
a

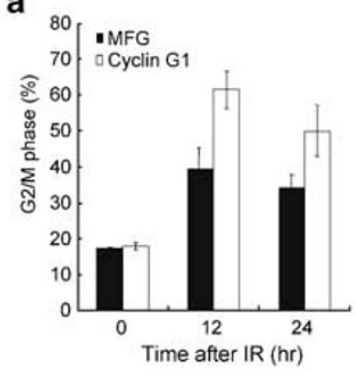

$\mathrm{NCl}-\mathrm{H} 460$

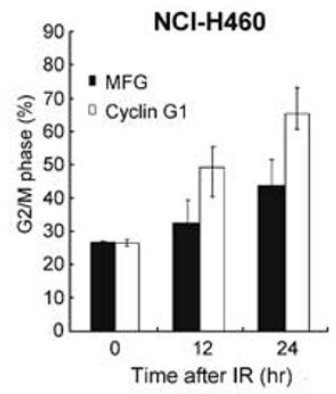

WI 38

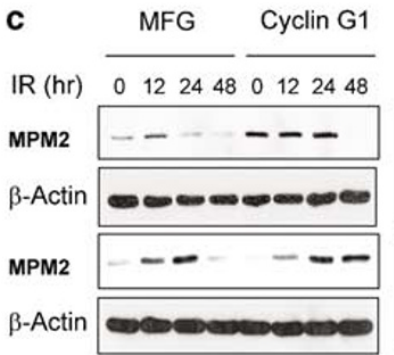

b

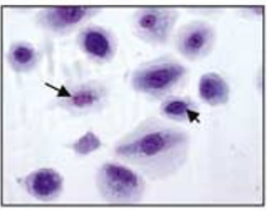

MFG

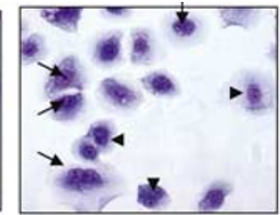

Cyclin G1 $-M F G$ + Cycin $\mathrm{G} 1$
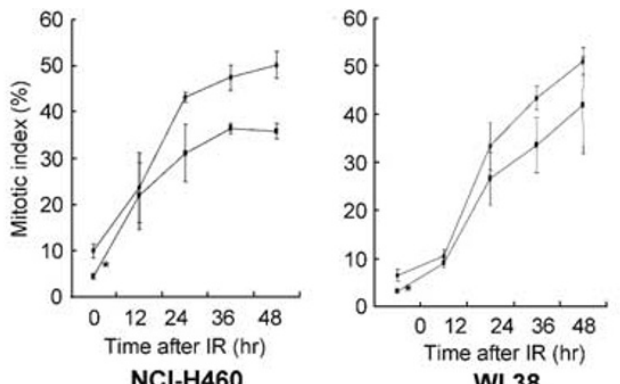

WI 38

d

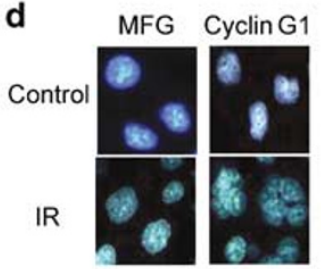

MFG Cyclin G1

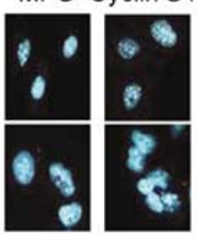

WI 38

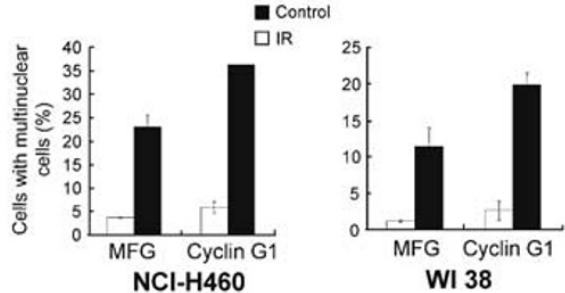

Figure 2 Radiation-induced G2 arrest was abrogated by cyclin G1. (a) At 12 and $24 \mathrm{~h}$ after radiation, flow cytometry analysis after PI staining was determined in control and cyclin G1 overexpressing cells. (b) Morphological analysis after Giemsa staining in 5 Gy radiation treated NCl-H460 cells. Arrow indicated mitotic cells (upper) and mitotic index was calculated (lower). (c) Western blot analysis for MPM-2 was performed at indicated time points of 5 Gy radiation. (d) Multinucleated giant cells were counted at $48 \mathrm{~h}$ after $5 \mathrm{~Gy}$ radiation. Results are means and standard deviation of three independent experiments

\section{Radiation sensitivity by cyclin G1 was abolished by treatment of cyclin B1 siRNA}

To elucidate whether increased sensitivity and mitotic arrest by radiation was mediated by cyclin B1, cyclin G1 overexpressing cells were treated with siB1. As seen in Figure 6a and $b$, increased cell death and G2/M phase by radiation in cyclin G1 overexpressing cells was attenuated by treatment with siB1 as well as siG1. Increased expression of cyclin B1 and $\mathrm{H} 2 \mathrm{AX}$ by radiation in cyclin $\mathrm{G} 1$ overexpressing cells was also diminished whereas the reduced expression of p21 by cyclin $\mathrm{G} 1$ was restored (Figure $6 \mathrm{c}$ ). Indeed, when mitotic index was examined under a microscopy after Giemsa staining, increased number of radiation induced mitotic cells by cyclin $\mathrm{G} 1$ was reduced after siG1 or siB1 (Figure 6d). These results indicate that the increase of mitotic cells and cell death by radiation was mediated by cyclin B1 in cyclin $\mathrm{G} 1$ ovexpressing cells.

\section{Cyclin G1 transcriptionally regulated cyclin B1 expression}

Since siRNA for cyclin $\mathrm{G} 1$ reduced the expression level of cyclin B1 protein, we examined whether cyclin $\mathrm{G} 1$ regulates cyclin B1 transcriptionally or post-translationally. Real-time RT-PCR analysis revealed that mRNA of cyclin B1 was increased in the cyclin G1 overexpressing cells, while the increased mRNA of cyclin B1 was reduced when siRNA for cyclin G1 was cotransfected (Figure 7a). Increased cyclin B1 promoter activity also indicated that cyclin $\mathrm{G} 1$ was directly involved in transcriptional level of cyclin B1 (Figure 7b). Since cyclin $\mathrm{G} 1$ has been shown to promote cell growth, ${ }^{6}$ nocodazole was employed to inhibit cell growth in order to exclude the possibility that cyclin $B 1$ regulation by cyclin $\mathrm{G} 1$ is not associated with cyclin G1-mediated growth facilitation. Increased cyclin B1 promoter activity was still present in the cyclin G1 overexpressing cells, even though nocodazole was 

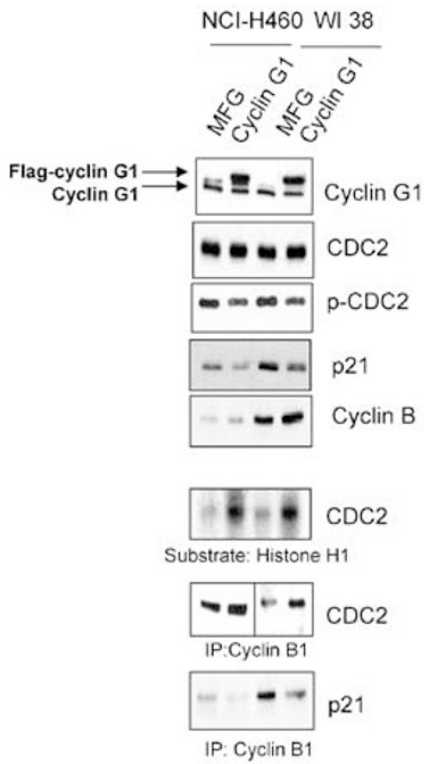

b

IR (hr) $\quad \frac{\text { MFG }}{0122448} \frac{\text { Cyclin G1 }}{0122448}$

p21

Cyclin B1

p53

B-Actin
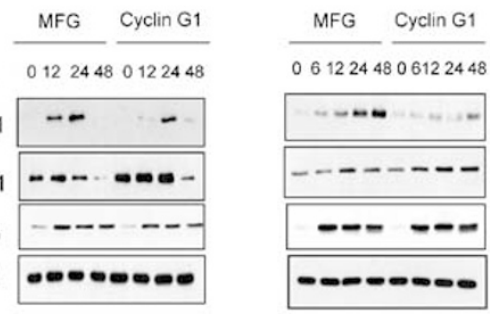

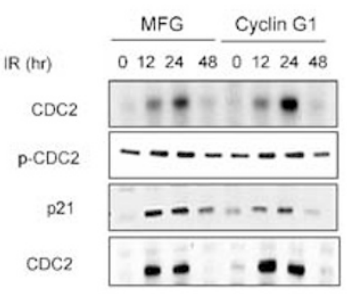

$\mathrm{NCl}-\mathrm{H} 460$

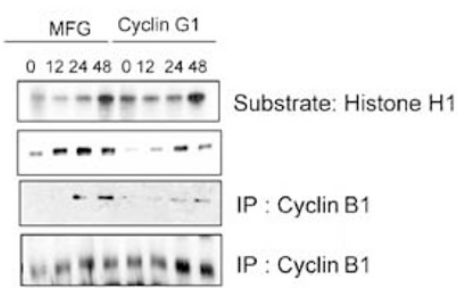

WI 38

Figure 3 Cyclin $\mathrm{G} 1$ inhibited cell cycle regulators related to the radiationinduced G2 arrest. (a) Western blot or immunoblotting after immunoprecipitation was performed in control and cyclin G1 overexpressing cells. (b) At indicated time points of 5 Gy radiation, Western blot or immunoblotting after immunoprecipitation was performed. Result represents one of three independent experiments

used to inhibit cell growth, accompanied with increased cyclin B1 protein levels (Figure 2d).

\section{Discussion}

Irradiation elicits various cellular response such as protein synthesis, activation of proteins as well as activation of cell cycle checkpoints that delay the progression of cell growth. ${ }^{22}$ Irradiation activates checkpoints at the transition from $\mathrm{G} 1$ to $S$ phase, in the $S$ phase, and at the transition from the $G 2$ phase to mitosis. ${ }^{22}$ Or if the damage is too much to handle, cells induce cell death or apoptosis. Here, we noted that understanding of the mechanisms by which cyclin G1 regulates the checkpoints for cell survival or for apoptosis are scarce. a
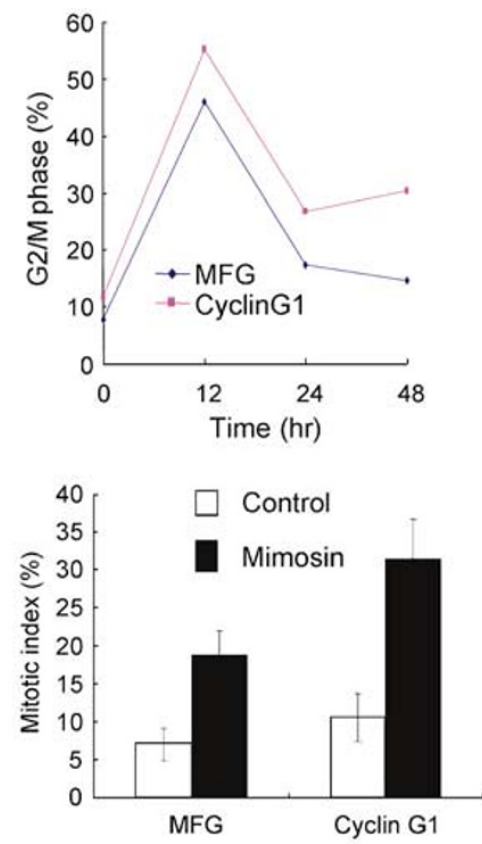

b $\frac{\text { MFG }}{0122448} \frac{\text { Cyclin G1 }}{0122448}$

Mimosine wash out (hr) 01224480122448

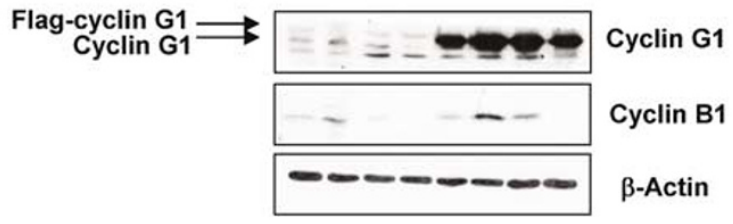

C Cyclin G1 Cyclin B1

-FITC -TRITC Merge Mimosine wash out (hr)
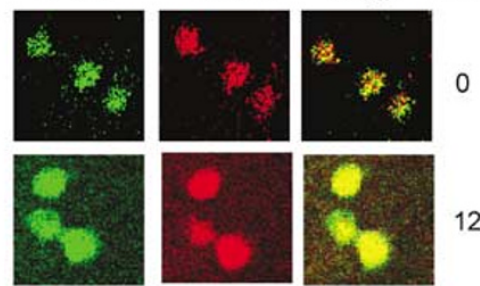

Figure 4 Cyclin G1 predominantly expressed in G2/M phase. (a) After overnight treatment with $200 \mu \mathrm{M}$ mimosine, cells were cultured with new media. Flowcytometry at indicated time points of mimosine wash-out was performed (upper) and multinucleated giant cells were counted at $12 \mathrm{~h}$ of mimosine washout (lower). (b) Western blot analysis was performed at indicated time points of mimosine wash-out (upper) and immufluorescence analysis using anticyclin G1 antibody for the time indicated. PI was used as counter staining for nucleus (lower). Results are means and standard deviation of three independent experiments

In the present study, we showed that cyclin G1, which is one of the radiation response genes in peripheral blood lymphocytes $^{17}$ and frequently overexpressed in tumor tissues, ${ }^{5,6,18}$ was found to inhibit radiation-induced G2 arrest with consequent increase in mitotic cells. Increased mitotic index by cyclin $\mathrm{G} 1$ seems to result from transcriptional upregulation of cyclin B1. Hence, our findings demonstrate that cyclin G1 enhanced radiation sensitivity by overriding $\mathrm{G} 2$ arrest through upregulation of cyclin B1 and mitotic index. 

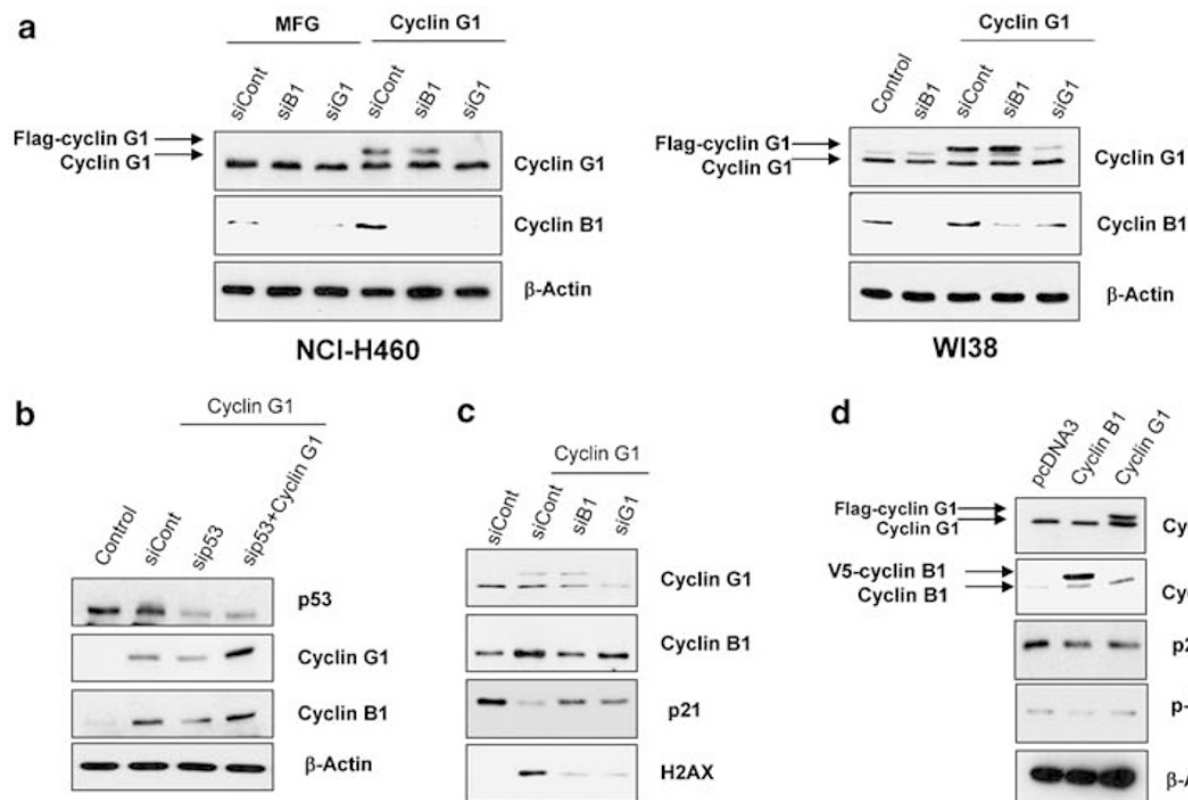

C

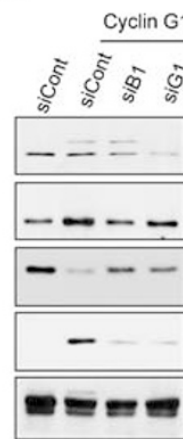

d

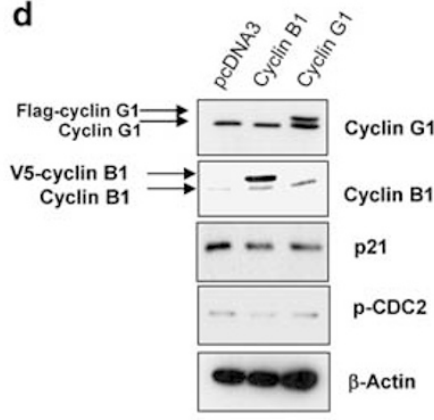

Figure 5 Cyclin G1 regulated cyclin B1 expression. (a, c) Control or cyclin G1, or cyclin B1 siRNAs (siCont, siG1 or siB1) were transfected to control and cyclin G1 overexpressing cells, and Western blot analysis was performed. (b) Control or p53 siRNAs (sip53) with or without additional cyclin G1 transfection were added to control and cyclin G1 overexpressing NCl-H460 cells, and Western blot analysis for cyclin B1 and cyclin G1 was performed. (d) Cyclin G1 or cyclin B1 was transiently overexpressed in $\mathrm{NCl}-\mathrm{H} 460$ cells, and Western blot was performed. Results present one of three independent experiements

In our tissue array data, cyclin G1 was frequently overexpressed in tumor tissues, including astrocytoma, melanoma, esophagus carcinoma, lung carcinoma, breast carcinoma, cervix, uterus, ovary, prostate and liver cancer (data not shown except for lung carcinoma). A report also indicated similar overexpression of cyclin G1 in leiomyoma tissue. ${ }^{6}$ However, exact mechanism of how cyclin G1 was overexpressed in tumor tissues remains unclear, even though no detectable mutation of p53 was observed. Cyclin G1 expression is specific to nucleus, and a report suggests that cyclin G1 may function by association with replication foci protein such as proliferating cell nuclear antigen. ${ }^{6}$ Ectopic overexpression of cyclin G1 in human RKO colon carcinoma cell line accelerated cell growth, and transfection of normal human fibroblasts with cyclin $\mathrm{G} 1$ increased the proliferative lifespan of the fibroblasts, ${ }^{23}$ suggesting that cyclin $\mathrm{G} 1$ may be associated with oncogenic potential.

Although the precise function of cyclin $\mathrm{G} 1$ remains unclear, it has been suggested to contribute to $\mathrm{G} 2 / \mathrm{M}$ arrest of cells in response to DNA damage ${ }^{24}$ and play a role in apoptosis. ${ }^{8}$ Thus, the function of cyclin G1 may involve growth control, induction of apoptosis or DNA repair following cellular damage caused by various stress stimuli.

In the present study, cyclin $\mathrm{G} 1$ overexpression in $\mathrm{NCl}-\mathrm{H} 460$ and WI38 lung cells was shown to increase radiosensitivity and radiation damage when $\mathrm{H} 2 \mathrm{AX}$ phosphorylation was detected, suggesting that cyclin $\mathrm{G} 1$ sensitized cells to radiation damage. Indeed, transplantation of cyclin $\mathrm{G} 1$ overexpressing $\mathrm{NCl}-\mathrm{H} 460$ cells to nude mice dramatically inhibited growth rate by radiation (data not shown), suggesting that cyclin G1 overexpressing tumors had increased sensitivity to radiation (Figure 1) and are more prone to radiation therapy. To elucidate the mechanism of radiation sensitization by cyclin $\mathrm{G} 1$, cell cycle distribution and morphological analysis were performed after radiation. Inhibition of radiation-induced G2 arrest and increase of mitotic cells by radiation were evident in cyclin G1 overexpressed cells. The CDC2-cyclin B1 complex plays a critical role, ${ }^{25}$ and the kinase activity of CDC2 is controlled during the cell cycle by both its association with cyclin B1 and phosphorylation status on the inhibitory phosphorylation sites. Cyclin B1 overexpression is also observed in various carcinomas, including esophageal squamous cell carcinoma, laryngeal squamous cell carcinoma and colorectal carcinoma. ${ }^{26-29}$ In the present study, cyclin G1 overexpression increased cyclin B1 expression, accompanied with increased CDC2 kinase activity with or without radiation, whereas the expression of $\mathrm{p} 21$, which is known as a broad range CDK inhibitor, was downregulated, suggesting inhibition of radiation-induced $\mathrm{G} 2$ arrest by cyclin $\mathrm{G} 1$. Because cyclin B1 expression by cyclin $\mathrm{G} 1$ was transcriptionally regulated (Figure 7), we suggest that increased cyclin B1 by cyclin $\mathrm{G} 1$ may be involved in CDC2 kinase activity with no change of CDC2 protein level, downregulation of p21 protein level, and finally inhibiting G2 arrest. Indeed, when cyclin B1 was overexpressed, the levels of phospho-CDC2 and p21 were inhibited (Figure 5). We do not know the mechanism of how cyclin B1 is regulated by cyclin G1. However, cyclin G1 transcriptionally activated cyclin B1 apparently independent of growth control (Figure 7b).

In mammalian cells, G2-M transition is controlled by the mitotic cyclin $\mathrm{B} 1 .^{30}$ The expression of cyclin $\mathrm{B} 1$ is regulated during the cell cycle, peaking at the G2-M transition. It has 
a

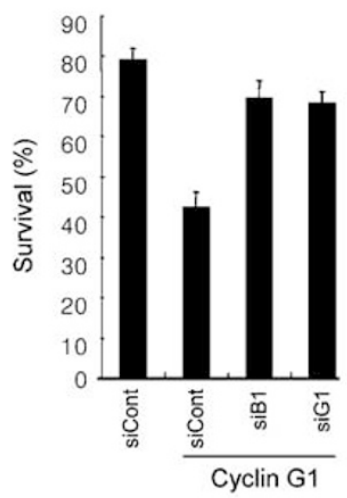

b

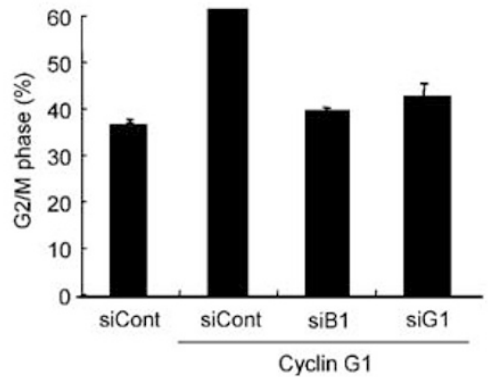

C

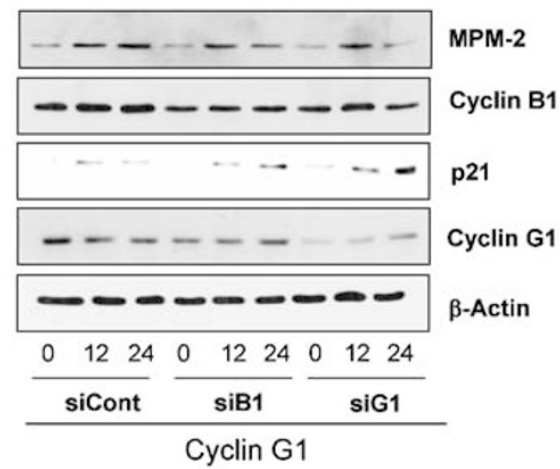

d

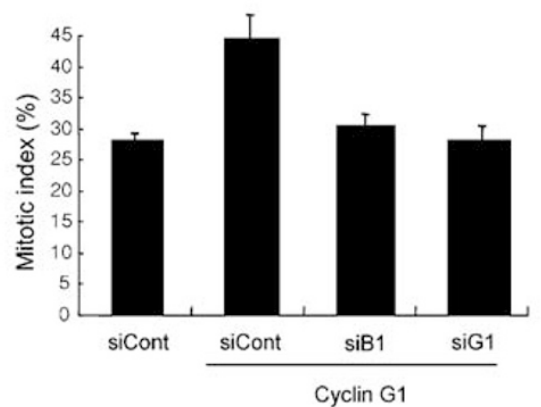

Figure 6 Radiation sensitivity by cyclin G1 was mediated by cyclin B1. Control or cyclin $\mathrm{G} 1$, or cyclin B1 siRNAs (siCont, siG1 or siB1) were transfected to control and cyclin $\mathrm{G} 1$ overexpressing $\mathrm{NCl}-\mathrm{H} 460$ cells. Flow cytometric analysis after PI staining was performed (a), cell cycle distribution after PI staining was determined (b), and mitotic arrested cells were counted (d). (c) At indicated time points of 5 Gy radiation, Western blot was performed. Results are means and standard deviation of three independent experiments

been known that the transcriptional activity of human cyclin B1 promoter is induced during the G2-M transition and repressed in $\mathrm{G} 1{ }^{31-34}$ However, it has not yet been demonstrated whether the cyclin B1 promoter retains transcriptional activity

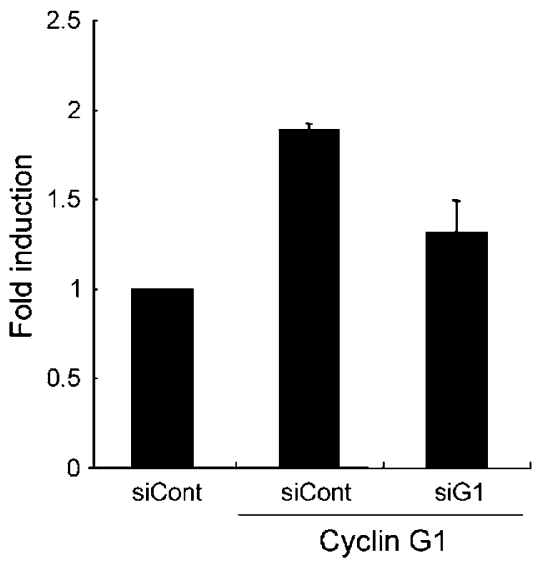

b

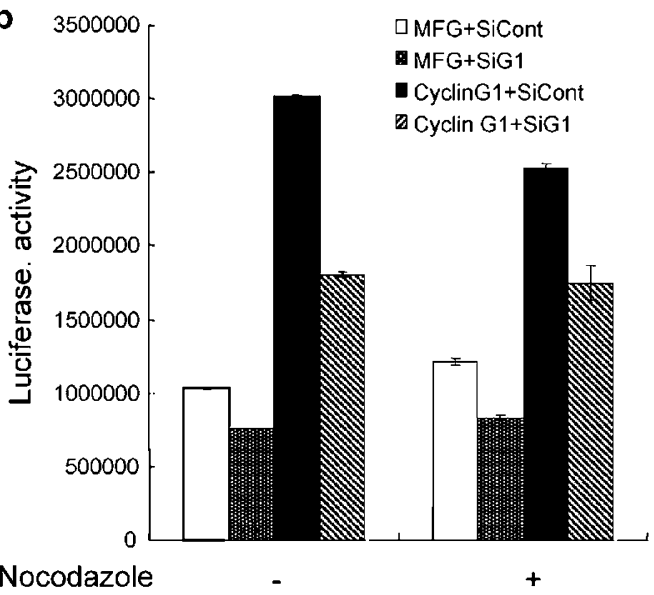

Figure 7 Cyclin G1 regulated cyclin B1 transcriptionally. Real-time RT-PCR analysis (a) and luciferase reporter gene assay for cyclin B1 promoter (b) with or without $12 \mathrm{~h}$ nocodazole $(1 \mu \mathrm{M})$ treatment were performed at $24 \mathrm{~h}$ of transient transfection with siRNAs of control or cyclin G1 (siCont or siG1) in control and cyclin G1 overexpressing cells. Results are means and standard deviation of three independent experiments.

during mitosis. After DNA damage by ionizing radiation, mammalian cells are arrested at the transition from $G 1$ to $S$ phase or from $\mathrm{G} 2$ to $M$ phase in the cell cycle, thus preventing DNA replication and mitosis in the presence of DNA damage. A recent report that the expression of wild-type p53 in human cells leads to an increase of $\mathrm{G} 2$ as well as $\mathrm{G} 1$ populations of the growth-arrested cells ${ }^{35}$ suggests that p53 regulates the G2-M transition. However, in a certain system, p53 expression does not clearly indicate the regulatory role of $p 53$, specifically in G2-M transition. In our present experiment, p53 expression was not changed by cyclin $\mathrm{G} 1$ overexpression, and p53 induction patterns by radiation were not different between the control and cyclin G1 overexpressing cells, either. Treatment of p53 siRNA reduced cyclin G1 and cyclin B1 expressions. However, when the cyclin $\mathrm{G} 1$ expression which is one of p53 target genes was recovered, p53 protein expression was still downregulated, while cyclin B1 expression was inhibited (Figure 5), suggesting that cyclin B1 regulation by cyclin $\mathrm{G} 1$ is independent of p53 expression. Moreover, radiosensitivitiy by cyclin $\mathrm{G} 1$ was correlated with cyclin B1. Treatment of cyclin B1 siRNA restored clonogenic survival after radiation to the control level, and similar 
tendency was also observed with the treatment of cyclin G1 siRNA. The number of cells with G2/M phase and mitotic cells by radiation were also reduced to the level of control cells by cyclin B1 siRNA treatment, while cyclin G1 overexpressed cells showed high mitotic cells, suggesting that cyclin B1 expression by cyclin $\mathrm{G} 1$ is responsible for the inhibition of $\mathrm{G} 2$ arrest by radiation, subsequently resulting in increased cell death. One defining feature of cells undergoing this form of cell death is the presence of giant and multinucleated cells (Figure 2d). Some reports indicate that escape of damaged cells from G2 arrest shares a common pathway with apoptosis-inducing cell death ${ }^{36-38}$ and our results also showed that cyclin G1 potentiated cell death via inhibition of radiation-induced $\mathrm{G} 2$ arrest following ionizing radiation.

In conclusion, the above results indicate that cyclin $\mathrm{G} 1$ overcame radiation-induced G2 arrest and increased cell death through transcriptional activation of cyclin B1, and that cyclin G1 overexpressing cancer tissue might clinically be more sensitive to radiation.

\section{Materials and Methods}

\section{Reagents}

Mimosine, nocodazole and monoclonal antibody for phospho-CDC2 were purchased from Sigma (St. Louis, MO, USA), monoclonal antibodies for cyclin G1, cyclin B1, CDC2, p21, and p53 were from Santa Cruz Biotechnology (Santa Cruz, CA, USA), and phospho-H2AX, MPM-2 and histone $\mathrm{H} 3$ were from Upstate (Charlottesvill, VA, USA).

\section{Plasmids and transfection}

For overexpression of cyclin $\mathrm{G} 1$, human cyclin $\mathrm{G} 1 \mathrm{cDNA}$ was cloned into murine leukemia virus MFG vector. This vector was constructed by an insertion of FLAG-tagged cyclin G1 cDNA between Ncol restriction site and $B a m H I$ restriction site on env region of wild-type virus genome. The MFG-cyclin G1 vector was transfected into the BD RetroPack ${ }^{\mathrm{TM}}$ PT67 cell line (Cat. No. 631510, BD Biosciences Clontech, Becton Drive, Franklin Lakes, NJ, USA). Virus produced by these cells was used to overexpress FLAG-cyclin $\mathrm{G} 1$ in $\mathrm{NCl}-\mathrm{H} 460$ or WI38. For overexpression of cyclin B1, human cyclin B1 cDNA was cloned into pcDNA4/V5-His (Invitrogen). This vector was constructed by an insertion of cyclin B1 cDNA between BamHI restriction site and $X$ hol restriction site on PcDNA4/V5-His, which contains C-terminal V5-epitope. The cyclin B1 promoter-firefly luciferase reporter construct hB1-Luci was kindly provided by Kurt Engeland. ${ }^{39}$ Predesigned siRNA for human cyclin G1, cyclin B1, p53 (Ambion Cat\# 19706, 51187, 16706) and negative control siRNA were purchased from Ambion, Inc. (Austin, TX, USA). The cells were transfected with the siRNAs for $48 \mathrm{~h}$ with the use of Lipofectamin ${ }^{\mathrm{TM}} 2000$ (Invitrogen). A mixture of $250 \mu \mathrm{l}$ of OptiMEM medium (Invitrogen) and $20 \mu \mathrm{l}$ of Lipofectamin ${ }^{\mathrm{TM}} 2000$ was incubated for $5 \mathrm{~min}$ at room temperature and was then combined with $100 \mathrm{nM}$ siRNA diluted with $250 \mu \mathrm{l}$ of Opti-MEM. The resulting mixture $(500 \mu$ l) was incubated for $20 \mathrm{~min}$ at room temperature to allow complex formation and then overlaid onto each well, containing the cells, in a final $2.5 \mathrm{ml}$ volume per $60-\mathrm{mm}$ dish.

\section{Cell culture}

$\mathrm{NCl}-\mathrm{H} 460$ human non-small-cell carcinoma and WI38 human lung fibroblast cells were cultured in RPMI (GIBCO, Gaithersburg, MD,
USA) supplemented with heat-inactivated $10 \%$ fetal bovine serum (FBS, GIBCO) and antibiotics at $37^{\circ} \mathrm{C}$ in a humidified incubator with $5 \% \mathrm{CO}_{2}$.

\section{Irradiation}

Cells were plated in $60 \mathrm{~mm}$ dishes and incubated at $37^{\circ} \mathrm{C}$ under humidified $5 \% \mathrm{CO}_{2}$ in culture medium until $70-80 \%$ confluent. Cells were then exposed to $\gamma$-rays with ${ }^{137} \mathrm{Cs} \gamma$-ray source (Atomic Energy of Canada, Ltd, Canada) with dose rate of $3.81 \mathrm{~Gy} / \mathrm{min}$.

\section{Colony-forming assay}

Clonogenicity was examined by colony-forming assay, as described previously. ${ }^{40,41}$ Cells were seeded into $60 \mathrm{~mm}$ dishes at densities to produce $\sim 500$ colonies per dish in the control and were incubated for 7-14 days. Colonies were fixed with a mixture of $75 \%$ methanol and $25 \%$ acetic acid, and stained with $0.4 \%$ Trypan blue. The number of colonies consisting of 50 or more was scored.

\section{Detection of cell death}

Cells were plated on glass slides and irradiated. After 24 or $48 \mathrm{~h}$, cells were fixed in $70 \%$ ethanol, washed with PBS, and incubated with $1 \mu \mathrm{g} / \mathrm{ml}$ bisbenzimide trihydrochloride in PBS (Heochst 33258) for $30 \mathrm{~min}$ in dark. Specimens were viewed by fluorescence microscopy using Olympus BX-40 microscope. At least 200 cells for each determination were scored. Apoptosis was characterized by chromatin condensation and fragmentation

\section{Cell cycle analysis}

For cell cycle analysis, cells were fixed in $80 \%$ ethanol at $4{ }^{\circ} \mathrm{C}$ for at least $18 \mathrm{~h}$. The fixed cells were then washed once with PBS-EDTA and resuspended in $1 \mathrm{ml}$ of PBS. After the addition of $10 \mu \mathrm{l}$ each of propodium iodide $(5 \mathrm{mg} / \mathrm{ml})$ and RNase $(10 \mathrm{mg} / \mathrm{ml})$, the samples were incubated for $30 \mathrm{~min}$ at $37^{\circ} \mathrm{C}$ and analyzed with a FACScan flow cytometer (Becton Dickinson, Franklin Lakes, NJ, USA).

\section{Immunoprecipitation}

Cells $\left(1 \times 10^{7}\right)$ were lysed in immunoprecipitation buffer $(50 \mathrm{mM}$ HEPES $\mathrm{pH} 7.6,150 \mathrm{mM} \mathrm{NaCl}, 5 \mathrm{mM}$ EDTA, 0.1\% NP-40). After centrifugation $(10 \mathrm{~min}$ at $15000 \mathrm{~g})$, to remove particulate material, the supernatant was incubated with antibodies $(1: 100)$ against anti-p21 p27 or cyclin B1 with constant agitation at $4^{\circ} \mathrm{C}$. The immunocomplexes were precipitated with protein A-Sepharose (Sigma) and analyzed by SDS-polyacrylamide gel electrophoresis using enhanced chemiluminescence detection (Amersham International).

\section{CDC2 kinase assay}

Cell lysates were incubated with CDC2 antibody, and immunocomplexes were collected on protein A-Sepharose beads and resuspended in kinase assay mixture containing $\left[\gamma^{32} \mathrm{P}\right]$ ATP (NEN Life Science, Boston, MA, USA) and histone $\mathrm{H} 1$ (Life Technologies, Inc., Paisley, Scotland, UK) as substrates. Proteins were separated on SDS-polyacrylamide gels, and bands were detected by autoradiography. 


\section{Polyacrylamide gel electrophoresis and Western blot}

For polyacrylamide gel electrophoresis (PAGE) and Western blot, cells were solubilized with lysis buffer $(120 \mathrm{mM} \mathrm{NaCl}, 40 \mathrm{mM}$ Tris ( $\mathrm{pH} 8.0), 0.1 \%$ NP40), the samples were boiled for $5 \mathrm{~min}$, and equal amount of protein ( $40 \mu \mathrm{g} /$ well) was analyzed on $10 \%$ SDS-PAGE. After electrophoresis, proteins were transferred onto a nitrocellulose membrane and processed for immunoblotting. Blots were further incubated with horseradish peroxidase-conjugated secondary antibody diluted at 1:5,000, and specific bands were visualized by chemiluminescence (ECL, Amersham International). Autoradiographs were recorded onto X-Omat AR films (Eastman Kodak Co.).

\section{Quantitative real-time PCR}

Real-time PCR analysis was performed using a DNA Engine2.OPTICON (MJ Reserch) and the LightCycler-FastStart DNA Master SYBR Green I mix (Roche). 3'-locked nucleic acid (LNA) primers were synthesized by Proligo. Reactions were performed in a final volume of $15 \mu \mathrm{l}$, adjusted to $4 \mathrm{mM} \mathrm{MgCl}_{2}$ and containing $500 \mathrm{nM}$ each of primers and $2 \mu \mathrm{l}$ of DNA template. The real-time PCR cycling conditions were as follows: $94^{\circ} \mathrm{C}$ for $5 \mathrm{~min}$, followed by 32 cycles for $1 \mathrm{~min}$ at $94^{\circ} \mathrm{C}, 1 \mathrm{~min}$ at $52^{\circ} \mathrm{C}$ and $2 \mathrm{~min}$ at $72^{\circ} \mathrm{C}$ followed by fluorescence measurement. The polymerization temperature was set to $68^{\circ} \mathrm{C}$ to allow accurate fluorescence measurements, because of the low-melting temperature of the PCR products analyzed. Following PCR, a thermal melt profile was performed for amplicon identification. To determine the $\mathrm{Ct}$, the threshold level of fluorescence was set manually in the early phase of the PCR amplification.

\section{Immunofluorescence analysis}

For immunofluorescence analysis, cells were fixed with $2 \%$ paraformaldehyde, permeabilized with $0.1 \%$. Triton $X-100$ in PBS, and then washed three times with PBS. Cells were then incubated with anticyclin $\mathrm{G1}$ diluted 1:200 in PBS with 5\% FBS for $1 \mathrm{~h}$ at room temperature in a humidified chamber. Excess antibody was removed by washing coverslips three times with PBS. Cells were then incubated with fluorescein isothiocyanate (FITC)-conjugated secondary antibody (Dako, Produktionsvej, Denmark), at $1: 200$ dilution in PBS with $5 \%$ FBS for $4 \mathrm{~h}$, and then incubated with $0.5 \mu \mathrm{g} / \mu \mathrm{l}$ propodium iodide (Molecular Porbes, Inc., Eugene, OR, USA) for $5 \mathrm{~min}$ at room temperature. After washing three times with PBS, coverslips were mounted onto microscope slides using ProLong antifade mounting reagent (Molecular Probes). The slides were analyzed by a confocal laser-scanning microscope (Leica Microsystems).

\section{Immunohistochemistry}

Various cancer tissues with corresponding normal tissues were arrayed from formal formalin-fixed and paraffin-embedded tissues of AccuMax array (Petagen Inc., Seoul, Korea), and these arrayed slides were used for the immunostaining of cyclin G1. Deparaffinization and rehydration were performed using xylene and alcohol, and pretreated slides were incubated in $3 \% \mathrm{H}_{2} \mathrm{O}_{2}$ for $13 \mathrm{~min}$ to remove endogenous peroxidase activity. The tissue was reacted with primary anticyclin $\mathrm{G} 1$ for $2 \mathrm{~h}$ in a humid chamber at room temperature and washed with PBS for $10 \mathrm{~min}$, and the sections were incubated for $20 \mathrm{~min}$ at room temperature with secondary antibody. After additional incubation with streptavidin-HRP for $10 \mathrm{~min}$, chromogen reaction was developed for $10 \mathrm{~min}$ in 3,3'-diaminobenzidien. The sections were counterstained with Harris' hematoxylin, dehydrated, and mounted with coverslips.

\section{Acknowledgements}

This work was supported by the Korea Science and Engineering Foundation (KOSEF) and by the Ministry of Science and Technology (MOST) through the National Nuclear Technology Program.

\section{References}

1. Okamoto $\mathrm{K}$ and Beach $\mathrm{D}$ (1995) Cyclin $\mathrm{G}$ is a transcriptional target of the $\mathrm{p} 53$ tumor suppressor protein. EMBO J. 13: 4816-4822

2. Zauberman $A$, Lupo $A$ and Oren $M$ (1995) Identification of $p 53$ target genes through immune selection of genomic DNA: the cyclin G gene contains two distinct p53 binding sites. Oncogene 10: 2361-2366

3. Kanaoka Y, Kimura SH, Okazaki I, Ikeda M and Nojima H (1997) GAK: a cyclin $\mathrm{G}$ associated kinase contains a tensin/auxilin-like domain. FEBS Lett. 402: 73-80

4. Kimura SH, Tsuruga $H$, Yabuta N, Endo $Y$ and Nojima $H$ (1997) Structure, expression, and chromosomal localization of human GAK. Genomics 44: 179-187

5. Reimer CL, Borras AM, Kurdistani SK, Garreau JR, Chung M, Aaronson SA and Lee SW (1999) Altered regulation of cyclin $G$ in human breast cancer and its specific localization at replication foci in response to DNA damage in p53+/+ cells. J. Biol. Chem. 274: 11022-11029

6. Baek WK, Kim D, Jung N, Yi YW, Kim JM, Cha SK, Bae I and Cho CH (2003) Increased expression of cyclin $\mathrm{G} 1$ in leiomyoma compared with normal myometrium. Am. J. Obstet. Gynecol. 188: 634-649

7. Kimura SH and Nojima H (2002) Cyclin G1 associates with MDM2 and regulates accumulation and degradation of $p 53$ protein. Genes Cell 7: 869-880

8. Okamoto K and Prives C (1999) A role of cyclin $\mathrm{G}$ in the process of apoptosis. Oncogene 18: 4606-4615

9. Teyssier F, Bay JO, Dionet $C$ and Verrelle $P$ (1999) Cell cycle regulation after exposure to ionizing radiation. Bull. Cancer 86: $345-357$

10. Hartwell LH and Kastan MB (1994) Cell cycle control and cancer. Science 266: $1821-1828$

11. Morgan DO (1997) Cyclin dependent kinases, clocks, and microprocessors. Annu. Rev. Cell Dev. Biol. 13: 261-291

12. Gould KL and Murse P (1989) Tyrosine phosphorylation of the fission yeast cdc2+ protein kinase regulates entry into mitosis. Nature 342: 39-45

13. Krek W and Nigg EA (1991) Mutations of p34cdc2 phosphorylation sites induce premature mitotic events in HeLa cells: evidence for a double block to p34cdc2 kinase activation in vertebrates. EMBO J. 10: 3331-3341

14. Gautier J, Solomon MJ, Booher RN, Bazan JF and Kirschner MW (1991) Cdc25 is a specific tyrosine phosphatase that directly activates p34cdc2. Cell 67: $197-211$

15. Dunphy WG and Kumagai $A$ (1991) The cdc25 protein contains an intrinsic phosphatase activity. Cell 67: 189-196

16. Borgne A and Meijer $L$ (1996) Sequential dephosphorylation of $p 34 c d c 2$ on Thr-14 and Try-15 at the prophase/metaphase transition. J. Biol. Chem. 271: $27847-27854$

17. Kang CM, Park KP, Song JE, Jeoung DI, Cho CK, Kim TH, Bae S, Lee SJ and Lee YS (2003) Possible biomarkers for ionizing radiation exposure in human peripheral blood lymphocytes. Radiat. Res. 159: 312-319

18. Rimokh R, Berger F, Bastard C, Klein B, French M, Archimbaud E, Rouault JP, Santa Lucia B, Duret L, Vuillaume M, Coiffer B, Bryon P and Magoud JP (1994) Rearrangement of CCND1 (BCL1/PRAD1) $3^{\prime}$ untranslated region in mantle-cell lymphomas and t(11q13)-associated leukemias. Blood 83: 3689-3696

19. Banath JP, Macphail SH and Olive PL (2004) Radiation sensitivity, H2AX phosphorylation, and kinetics of repair of DNA strand breaks in irradiated cervical cancer cell lines. Cancer Res. 64: 7144-7149

20. Cho HN, Lee SJ, Park SH, Lee YJ, Cho CK and Lee YS (2001) Overexpression of heat-shock protein 25 augments radiation-induced cell-cycle arrest in murine L929 cells. Int. J. Radiat. Biol. 77: 225-233 
21. Zhao L, Samuels T, Winckler S, Korgaonkar C, Tompkins V, Horne MC and Quelle DE (2004) Cyclin G1 has growth inhibitory activity linked to the ARFMdm2-p53 and pRb tumor suppressor pathways. Mol. Cancer Res. 1: 195-206

22. Xu B, Kim ST, Lim DS and Kastan MB (2002) Two molecularly distinct G(2)/M checkpoints are induced by ionizing irradiation. Mol. Cell. Biol. 22: 1049-1059

23. Smith ML, Bortnick RA, Sheikh MS and Fornace Jr AJ (1998) Chromatin relaxation by overexpression of 1 . mutant p53, HPV16-E6, or cyclin G1 transgens. Exp. Cell Res. 242: 235-243

24. Shimizu A, Nishida J, Ueoka $Y$, Kato K, Hachiya T, Kuriaki $Y$ and Wake $N$ (1998) Cyclin $G$ contributes to G2/M arrest of cells in response to DNA damage. Biochem. Biophys. Res. Commun. 242: 529-533

25. King RW, Jackson P and Kirschner MW (1994) Mitosis in transition. Cell 79: 563-571

26. Dong Y, Sui L, Watanabe Y, Sugimoto $K$ and Tokuda M (2002) Clinical relevance of cyclin $B 1$ overexpression in laryngeal squamous cell carcinoma. Cancer Lett. 177: 13-19

27. Jin P, Hardy S and David OM (2002) Nuclear localization of cyclin B1 controls mitotic entry after DNA damage. J. Cell Biol. 141: 875-885

28. Takeno S, Noguchi T, Kikuchi R, Uchida Y, Yokoyama S and Müller W (2002) Prognostic value of cyclin B1 in patients with esophageal squamous cell carcinoma. Cancer 94: 2874-2881

29. Li JQ, Kubo A, Wu F, Usuki H, Fujita J, Bandoh S, Masaki T, Saoo K, Takeuchi H, Kobayashi S, Imaida K, Maeta H, Ishida T and Kuriyama S (2003) Cyclin B1, unlike cyclin $\mathrm{G} 1$, increases significantly during colorectal carcinogenesis and during later metastasis to lymph nodes. Int. J. Oncol. 22: 1101-1110

30. Jackman MR and Pines J (1997) Cyclins and the G2/M transition. Cancer Surv. 29: $47-73$

31. Cogswell JP, Godlevski MM, Bonham M, Bisi J and Babiss L (1995) Upstream stimulatory factor regulates expression of the cell cycle dependent cyclin B1 gene promoter. Mol. Cell. Biol. 15: 2782-2790

32. Hwang A, Maity A, McKenna WG and Muschel RJ (1995) Cell cycle dependent regulation of the cyclin B1 promoter. J. Biol. Chem. 270: 28419-28424
33. Piaggio G, Farina A, Perrotti D, Manni I, Fuschi P, Sacchi A and Gaetano C (1995) Structure and growth-dependent regulation of the human cyclin B1 promoter. Exp. Cell Res. 216: 396-402

34. Katula KS, Wright KL, Paul H, Surman DR, Nuckolls FJ, Smith JW, Ting JP, Yates $\mathrm{J}$ and Cogswell JP (1997) Cyclin dependent kinase activation and S-phase induction of the cyclin B1 gene are linked through the CCAAT elements. Cell Growth Differ. 8: 811-820

35. Park M, Chae HD, Yun J, Jung M, Kim YJ, Kim SH, Han MH and Shin DY (2000) Constitutive activation of cyclin B1-associated cdc2 kinase overrides p53-mediated G2-M arrest. Cancer Res. 60: 542-545

36. Ruth $A C$ and Roninson IB (2000) Effects of the multidrug transporter P-glycoprotein on cellular responses to ionizing radiation. Cancer Res. 60: 2576-2578

37. Yoshikawa R, Kusunoki M, Yanagi H, Noda M, Furuyama JI, Yamamura T and Hashimoto-Tamaoki T (2002) Dual antitumor effects of 5-fluorouracil on the cell cycle in colorectal carcinoma cells: a novel target mechanism concept for pharmacokinetic modulating chemotherapy. Cancer Res. 61: 1029-1037

38. Ling YH, Leibes L, Jiang JD, Holland JF, Elliott PJ, Adams J, Muggia FM and Perez-Soler R (2003) Mechanisms of proteasome inhibitor PS-341-induced G2-M Phase arrest and apoptosis in human non-small cell lung cancer cell lines. Clin. Cancer Res. 9: 1145-1154

39. Wasner M, Tschop K, Spiesbach K, Haugwitz U, Johne C, Mossner J, Mantovani R and Engeland K (2004) Cyclin B1 transcription is enhanced by the p300 coactivator and regulated during the cell cycle by a CHR-dependent repression mechanism. FEBS Lett. 536: 66-70

40. Cho HN, Lee YJ, Cho CK, Lee SJ and Lee YS (2002) Downregulation of ERK2 is essential for the inhibition of radiation-induced cell death in HSP25 overexpressed L929 cells. Cell Death Differ. 9: 448-456

41. Lee YJ, Soh JW, Dean NM, Cho CK, Kim TH, Lee SJ and Lee YS (2003) Protein kinase $C$ delta overexpression enhances radiation sensitivity via extracellular regulated protein kinase $1 / 2$ activation, abolishing the radiationinduced G(2)-M arrest. Cell Growth Differ. 13: 237-246 